\title{
Ethnologies
}

\section{Le Musée des cultures du monde à Lyon}

\section{Michel Côté}

Volume 24, numéro 2, 2002

Musées

Museums

URI : https://id.erudit.org/iderudit/006647ar

DOI : https://doi.org/10.7202/006647ar

Aller au sommaire du numéro

Éditeur(s)

Association Canadienne d'Ethnologie et de Folklore

ISSN

1481-5974 (imprimé)

1708-0401 (numérique)

Découvrir la revue

Citer cette note

Côté, M. (2002). Le Musée des cultures du monde à Lyon. Ethnologies, 24(2), 211-217. https://doi.org/10.7202/006647ar

\section{Résumé de l'article}

Le Muséum d'histoire naturelle de Lyon subit des transformations profondes. Ainsi au cours des prochains mois et des prochaines années, verront le jour le Centre de conservation et d'étude des collections, le Musée des Cultures du Monde et le Musée des Confluences. Le Musée des Cultures du Monde s'inscrit dans une longue tradition d'échanges entre Lyon et l'étranger. Créer un tel musée en 2004 suppose que l'on ait défini clairement un projet répondant aux questions suivantes : qui parle, de quoi parle-t-on et à qui parlons-nous ? Ce nouveau musée se veut thématique et pluridisciplinaire, traitant bien sûr de sujets exotiques et lointains, mais surtout d'enjeux culturels contemporains.
Ce document est protégé par la loi sur le droit d'auteur. L'utilisation des services d'Érudit (y compris la reproduction) est assujettie à sa politique d'utilisation que vous pouvez consulter en ligne.

https://apropos.erudit.org/fr/usagers/politique-dutilisation/ 
CARnet de Notes / Notebook

\section{Le Musée des cultures du monde à Lyon}

\section{Michel Côté}

Directeur du Muséum d'histoire naturelle de Lyon

Chef de projet du Musée des Confluences

Le Muséum d'histoire naturelle de Lyon a de riches collections (sciences de la terre, sciences de la vie et ethnographie) et une longue histoire. Mieux connu sous le vocable "Musée Guimet », cette institution a transmis le savoir à de nombreuses générations tout en marquant leur imaginaire.

Cependant le temps était venu de rénover l'institution, ne serait-ce que pour mieux l'adapter aux règles contemporaines de conservation. Le Conseil général du Rhône qui a la responsabilité de ce lieu a décidé de revoir au même moment le projet scientifique et culturel de cet établissement. Après consultation de divers milieux scientifiques, culturels, institutionnels et économiques, un plan de redéploiement du Muséum fut proposé et accepté par l'ensemble des élus du Conseil général.

Ces nouvelles orientations reposent sur un certain nombre de prémisses. Ainsi, le musée doit s'inscrire dans une démarche thématique et pluridisciplinaire. Le discours muséal ne peut pas reposer sur la seule mise en valeur des collections et l'analyse ne s'appuyer que sur une seule discipline. Ce courant de pensée que l'on retrouve dans de nombreux projets européens va jusqu'à privilégier des approches intégrant sciences humaines et sciences pures. Tous les moyens doivent être utilisés pour mieux comprendre la complexité du monde. 
Bien sûr, le musée doit privilégier une approche «visiteurs » en mettant l'accent, d'une part, sur la diversité thématique (variété des sujets abordés) et muséographique (faisant appel à l'ensemble de la grammaire muséographique : contemplation-manipulationthéâtralisation...) et, d'autre part, sur le traitement pluriel des sujets (théâtre, musique, danse, débats...)

Fondamentalement associée aux milieux universitaires, culturels et économiques, l'institution muséale privilégie une approche réseau fondée sur la complémentarité et le renforcement des actions culturelles.

Conscient de ces orientations, le Muséum redéploie son action en quatre lieux : un centre de conservation et d'étude sur les collections, un Musée des Cultures du Monde (situé dans l'actuel édifice, mais rénové), le domaine de Lacroix-Laval (mettant en valeur la relation nature-culture) et enfin le Musée des Confluences, musée de sciences et de sociétés.

Voici le contexte général et le climat de développement culturel du Conseil général. Vivre ce changement entraîne un certain nombre d'interrogations ayant trait bien sûr à la mission, aux publics et à notre action culturelle et muséale.

Le Pôle sciences et sociétés, qui regroupe les quatre composantes précédemment mentionnées, se retrouve en effet face à des défis administratifs (vivre le changement et l'instabilité), des défis budgétaires et des enjeux culturels. Oublions pour le moment le Musée des Confluences (même s'il constitue la pièce majeure du projet) et le Domaine de Lacroix-Laval pour nous concentrer sur la politique et la question des collections ethnologiques et le Musée des Cultures du Monde.

\section{Un projet}

Le Musée s'est donné une mission large, ne fixant ni limite géographique ni limite temporelle. Les cultures du monde ne doivent pas être perçues uniquement comme exotiques et lointaines mais aussi comme proches et actuelles. A l'heure des échanges interculturels, de la différence culturelle, de la mondialisation, du métissage, de l'immigration et de l'intégration, du multiculturalisme et du pluriculturalisme ...(et j'en passe) nous avons choisi de ne pas nous 
restreindre pour mieux faire des ponts entre le passé, le présent et l'avenir, entre l'ici et l'ailleurs, sachant que l'ailleurs est aussi ici.

Bien sûr, nous allons parler d'aires culturelles et de sociétés situées géographiquement, dans un temps et dans un espace, bien sûr, nous allons aborder des questions précises, des sujets historiques, mais nous allons aussi tenter de dégager ce qui constitue les fondamentaux des sociétés, les enjeux contemporains, les interrogations citoyennes. Nous allons passer de l'intime au collectif, de l'émotion de la vie au savoir et à l'analyse. Notre volonté : ne pas enfermer, mais laisser percevoir l'évolution et la complexité.

Déjà le Muséum a mis sur pied un certain nombre d'expositions et d'activités culturelles préfigurant le changement d'orientation. Une première exposition intitulée «Chef d'œuvres, trésors et quoi encore... » se voulait une réflexion sur la place de l'objet ethnologique dans le musée et sur le questionnement des types de discours du milieu muséal. Chaque partie était illustrée par un objet phare qui introduisait la sous thématique abordée. Un texte de Jean-Yves Loude, voyageur et ethnologue, accompagnait le visiteur tout au long de son parcours. Après une courte introduction où le visiteur était confronté à une variété d'objets de culture et d'époques différentes et aux discours de quatre intervenants culturels, il découvrait une première salle où étaient présentés des objets technologiques exploitant la notion de chefsd'œuvre et de performance technique (les compagnons du Tour de France illustrant bien ce discours); un deuxième espace était consacré au regard esthétique où des «classiques » de l'art africain, européen, inuit ou... romain illustraient la valorisation de certains objets ethnographiques: un bref passage démontrait par la suite le rôle des musées et la politique marchande face aux objets ethnologiques; puis était abordé l'objet comme témoin et révélateur d'une société, qu'elle soit exotique ou proche, et «l'objet madeleine » qui permettait à des personnes, célèbres ou non, de dévoiler les rapports affectifs qu'ils entretiennent avec un patrimoine perçu par d'autres comme banal. La dernière zone présentait par ailleurs des objets forts et porteurs de sens face à un enjeu social et collectif (ces objets prenaient d'ailleurs plusieurs formes puisque le témoignage y était intégré). Conclusion de l'exposition : derrière les objets il y a des sociétés, mais surtout des hommes et des femmes, des êtres vivants... Et c'est ce qui nous intéresse. 
Un musée des cultures du monde ne doit pas oublier qu'il est aussi le produit d'une culture contemporaine : il se doit de développer un dialogue constant entre la réalité de son point de vue et la réalité des autres sociétés ou groupes. Même si notre prétention est de donner la parole ou d'engager l'échange, nous savons très bien (et nous le revendiquons) que le discours présenté est notre discours, que les cultures du monde, c'est aussi notre culture.

\section{Des collections}

La question des collections du Musée des Cultures du Monde a fait bien sûr l'objet de nombreux débats. Il est facile de convenir de son importance et de sa richesse. Le célèbre «Homme Barbu » est demandé autant pour la représentation des chefs-d'œuvre du monde, au Pavillon des sessions, dans le cadre de la préfiguration du Musée du Quai Branly, que pour le Pallazio Grazzi dans le cadre de son exposition internationale sur l'égyptologie. Nous avons entrepris un vaste programme de conservation et de restauration des collections et la rénovation du Muséum s'inscrit dans cette volonté d'une protection accrue du patrimoine.

Une lecture de cette collection montre aussi des faiblesses : elle fut construite par des scientifiques avec des connaissances et la compréhension de l'époque, à partir d'une vision coloniale (l'ancien Musée colonial), d'une volonté religieuse (la propagation de la foi) et la compétence de conservateurs et de donateurs. Se baser uniquement sur cette collection, c'est évidemment donner une vision partielle et partiale de la réalité. Il est donc nécessaire de faire comprendre au visiteur que ce qu'il regarde répond à des choix et à des intentions.

Le Musée a une politique de développement de ses collections basée sur des acquisitions par achat et par des dons. Ces choix ne sont pas exempts de filtre. Par ailleurs, compte tenu de nos intérêts envers certaines communautés, le Musée a développé une série de séminaires nous permettant de mieux comprendre les enjeux liés aux acquisitions et à la protection du patrimoine, qu'il s'agisse de nos propres collections ou de collections d'autres institutions. Ainsi, les questions du droit d'auteur dans des sociétés de tradition orale (les premières nations) ou du rapatriement des collections (notamment en Afrique) ont été clairement posées. 
Compte tenu de notre projet culturel, nous ne pouvons nous contenter d'une approche classique d'acquisitions, même pro-active. Les collections doivent être perçues d'une façon globale et en réseau de partenariat avec d'autres lieux culturels et socio-économiques.

S'assurer de partager et de mettre en valeur le patrimoine, c'est accepter de travailler avec d'autres intervenants, de débattre d'enjeux de conservation, de faire les choix et permettre à d'autres d'agir... La mémoire collective de groupes d'individus est aussi de la responsabilité de ces groupes. Le Musée accompagne actuellement des associations citoyennes qui veulent reconstituer leur mémoire et identifier (par la parole, par l'écrit, par l'objet...) ce qui constitue leur identité.

Ces limites des collections, cette volonté de les enrichir, d'actualiser le propos, de diversifier les sources ne peut s'accomplir dans un absolu, mais en accord avec les choix culturels de l'exposition de synthèse et de référence qui définit le fil conducteur de l'institution et qui précise les thématiques générales. En effet, le Musée distingue deux types d'expositions. Au concept d'exposition permanente, qui n'a de sens que par rapport au temps, nous préférons la notion d'exposition de synthèse et de référence qui peut évoluer dans le temps mais qui garde toujours vivant le projet culturel de l'institution. Quant aux expositions temporaires, elles deviennent des expositions de déclinaison nous permettant de mettre l'accent sur une particularité ou au contraire d'ouvrir de nouvelles voies de réflexion et d'émotion.

Bien sûr, le musée est aussi appelé à réfléchir sur son impact global et sa diffusion. Aussi avons-nous élaboré ce concept de «musée nomade » qui nous permet de multiplier notre action hors nos murs et même dans des lieux non traditionnels.

Cette exposition de synthèse traitera donc des éléments constitutifs d'une société et d'une vie en société. Nous sommes d'abord d'un espace et d'un temps (le fait d'être constitué à partir d'un muséum d'histoire naturelle n'est sans doute pas étranger à cette section). Aussi, dans un premier temps, seront abordées les relations de la personne avec son environnement naturel et culturel. Nous sommes d'une société. Des pouvoirs nous conditionnent: l'État, l'Église, l'école (et même, soyons prétentieux, les musées) ; des pratiques et des modes d'expression prennent forme (création, recherche spirituelle, manifestations individuelles et collectives); des bilans se forment (malgré et avec les 
mémoires refoulées), des enjeux contemporains sociétaux s'offrent à nous.

On l'aura compris, l'exposition de synthèse et de référence pose la question de la complexité mais aussi des points d'ancrage de nos sociétés pour mieux rejoindre les préoccupations actuelles des visiteurs. Ainsi le Musée a identifié dans un premier temps une dizaine d'enjeux sociaux contemporains qui seront abordés dans l'exposition et qui découleront des découvertes des collections et des premiers parcours. Le visiteur sera confronté également à ses propres valeurs puisque, au sein de l'exposition, on retrouvera des valeurs contemporaines des Français. La culture française fait aussi partie des cultures du monde.

\section{Des publics}

Les publics demeurent par ailleurs au centre de nos préoccupations. Si l'exposition est perçue comme un discours (qu'il s'agisse d'ailleurs d'un roman, d'un essai ou d'une ouvre poétique), elle pose la question du destinataire. A qui nous adressons-nous? Aux Lyonnais et, parmi les Lyonnais, lesquels? Aux touristes? Aux groupes communautaires? Aux enfants?

Une récente étude de l'observatoire des publics démontre que certains musées ont une vocation ciblée notamment sur les touristes étrangers ou les touristes nationaux. Notre choix est plutôt de nous ancrer localement, sachant que le public local n'est pas que local. Nous sommes lyonnais, français, européens et citoyens du monde.

La question de la pérennité de notre action éducative et culturelle demeure. Comment pouvons-nous espérer jouer un rôle actif sans inscrire nos opérations dans la durée ? Les musées ne peuvent ignorer qu'ils ne s'adressent qu'à une partie de la population (environ 30\%). Si on peut s'interroger sur ces limites (manque d'intérêt pour les sujets présentés? Pour la muséographie ? Manque de communication ?) il faut voir comment les dépasser. Afin d'avoir une perception juste des attentes des visiteurs et de connaître leurs perceptions du musée, des cultures du monde ou de la muséologie, le Musée a décidé de créer des groupes témoins diversifiés sur le plan socio-économique. Ainsi une démarche d'accompagnement des attentes et des perceptions des publics fidèles et non fidèles a été mise sur pied. Objectif : diversification, élargissement et approfondissement. 


\section{Le locuteur}

Par ailleurs, les demandes d'accompagnement et de médiation ont été expérimentées et multipliées afin de trouver des réponses adaptées : que faisons-nous pour les membres des communautés culturelles, pour les analphabètes, pour les experts, pour les handicapés, pour le public de proximité, pour les jeunes, etc...?

De quoi parle le musée : à qui parle-t-il, mais aussi qui parle? Un Musée des Cultures du Monde ne peut se développer en vase clos; il entraîne un dialogue avec d'autres cultures et d'autres sociétés. Parfois il porte un regard extérieur et il le dit; parfois il laisse la parole et là aussi il le dit. Le visiteur doit comprendre que l'histoire racontée a une source et est portée par un ou des groupes. Ce travail constant entre l'expertise scientifique et l'expertise culturelle constitue un des enjeux fondamentaux.

Le programme culturel du Musée des Cultures du Monde est évidemment beaucoup plus large que les seules expositions. Sur le plan architectural, cela se note en voyant la création de nouveaux espaces découvertes, d'ateliers, d'un auditorium ou d'un café-concert. Poésie, théâtre, musique, danse sont appelés à la barre des témoins pour rendre compte de la vie et de l'expression de cette vie de cultures.

La véritable angoisse est de réduire un groupe à une idée ou à une image. Lors de l'élaboration du projet Cultures d'ados où le Musée a travaillé avec cinq groupes de jeunes de milieux divers sur la relation avec l'autre (le musée donnant un appui muséographique à l'expression de ces jeunes), un jeune handicapé nous a ramené à l'ordre en nous rappelant qu'il n'était pas qu'handicapé, mais bien un citoyen avec un point de vue. Sa différence avait fait oublier son intégralité.

Rentrer le monde dans quelques milliers de mètres carrés est évidemment un pari perdu d'avance. La vie ne saurait se réduire à une exposition. L'espoir, c'est qu'après une visite il reste des images et des émotions, des connaissances et surtout la curiosité et l'envie d'aller plus loin. Tout comme un article dans une revue, qui résume et rend compte, qui est une bouteille à la mer. 